\title{
Структура и термоэлектрические свойства CoSi, полученного из пересыщенного раствора-расплава в Sn
}

\author{
(C) Ф.Ю. Соломкин ${ }^{1}$, А.С. Орехов ${ }^{2,3}$, С.В. Новиков ${ }^{1}$, Н.А. Архарова ${ }^{2}$, Г.Н. Исаченко ${ }^{1}$, \\ Н.В. Зайцева ${ }^{1}$, Н.В. Шаренкова ${ }^{1}$, А.Ю. Самунин ${ }^{1}$, В.В. Клечковская ${ }^{2}$, А.Т. Бурков ${ }^{1}$ \\ ${ }^{1}$ Физико-технический институт им. А.Ф. Иоффе Российской академии наук, \\ 194021 Санкт-Петербург, Россия \\ ${ }^{2}$ Институт кристаллографии им. А.В. Шубникова Федерального научно-исследовательского центра \\ „Кристаллография и фотоника“ Российской академии наук, \\ 119333 Москва, Россия \\ ${ }^{3}$ Национальный исследовательский центр „Курчатовский институт“, \\ 123182 Москва, Россия \\ E-mail: f.solomkin@mail.ioffe.ru
}

Поступила в Редакцию 7 февраля 2019 г.

В окончательной редакции 10 февраля 2019 г.

Принята к публикации 14 февраля 2019 г.

Исследованы структура, состав и термоэлектрические свойства моносилицида кобальта, полученного из пересыщенного раствора-расплава в олове. Разработана методика синтеза и направленной кристаллизации микрокристаллического и объемного текстурированного материалов в одном технологическом цикле.

DOI: 10.21883/FTP.2019.06.47725.34

\section{1. Введение}

Моносилицид кобальта $(\mathrm{CoSi})$ - перспективный термоэлектрический материал $n$-типа проводимости с высоким фактором термоэлектрической мощности $S^{2} \sigma$ $(S-$ коэффициент термоэдс, $\sigma-$ электропроводность) [1]. Диаграмма состояний $\mathrm{CoSi}$ имеет широкую область гомогенности, по краям которой, согласно [2], Со и $\mathrm{Si}$ находятся в соотношении $\mathrm{Co}_{0.51} \mathrm{Si}_{0.49}$ и $\mathrm{Co}_{0.495} \mathrm{Si}_{0.505}$, что соответствует стехиометрическому интервалу $\mathrm{CoSi}_{0.96}-\mathrm{CoSi}_{1.02}$. Соответственно при разных условиях синтеза элементный состав материала может меняться, что сильно влияет на его транспортные свойства. Дополнительный интерес к $\mathrm{CoSi}$ связан с недавними теоретическими результатами по расчету электронной структуры этого соединения, которые показали, что электронный спектр $\mathrm{CoSi}$ вблизи уровня Ферми содержит зоны с линейным законом дисперсии и пересечениями с многократным вырождением [3-5]. Узлы пересекающихся зон находятся очень близко к уровню Ферми и характеризуются топологическим зарядом значительно больше единицы, поэтому CoSi и некоторые другие изоструктурные моносилициды относятся к классу полуметаллов с топологически нетривиальной электронной структурой, в которых топологические особенности спектра могут оказывать существенное влияние на электронный транспорт.

В данной работе исследована возможность получения микро- и макрокристаллов $\mathrm{CoSi}$ из пересыщенного раствора в расплаве. В качестве металла-растворителя использовалось олово. Исследовались термоэлектрические свойства, структура и микроструктура микро- и макрокристаллов.

\section{2. Материалы и методы}

Кристаллизация из пересыщенного раствора-расплава (PР) позволяет в одном технологическом цикле получать микрокристаллы, которые при охлаждении формируются в объеме расплавленного олова (рис. 1, 1-2), и массивные образцы из материала, который при кристаллизации вытесняется на поверхность раствора-расплава и образует слиток в форме линзы (рис. $1,1-3)$. В качестве растворителей подбираются металлы с низкой температурой плавления, высокой температурой кипения, низкой упругостью пара.

Для того чтобы обеспечить избыточное растворение материала в РР и вытеснение его избытка на поверхность при охлаждении, температура РP устанавливалась значительно выше температуры плавления CoSi и составляла 1923 К. Расплав выдерживался при 1923 K в течение 15 мин и затем охлаждался. Длительность охлаждения слитка до комнатной температуры в процессе прохождения температурного градиента (протяжка по методу Бриджмена) составляла 1.5 ч. После охлаждения слиток помещался в соляную кислоту для полного растворения олова.

Фазовый состав кристаллизованного вещества исследовали методом рентгеновской дифрактометрии (ДРОН-3, Сu $K_{\alpha}$-излучение). Морфологию, микроструктуру и химический состав образцов исследовали методами растровой электронной микроскопии (РЭМ) и рентгеновской энергодисперсионной спектрометрии (ЭДС) на микроскопах FEI Quanta 200 3D и FEI Scios FEG при ускоряющем напряжении от 5 до 30 кВТ в режимах вторичных и обратно рассеянных электронов. 


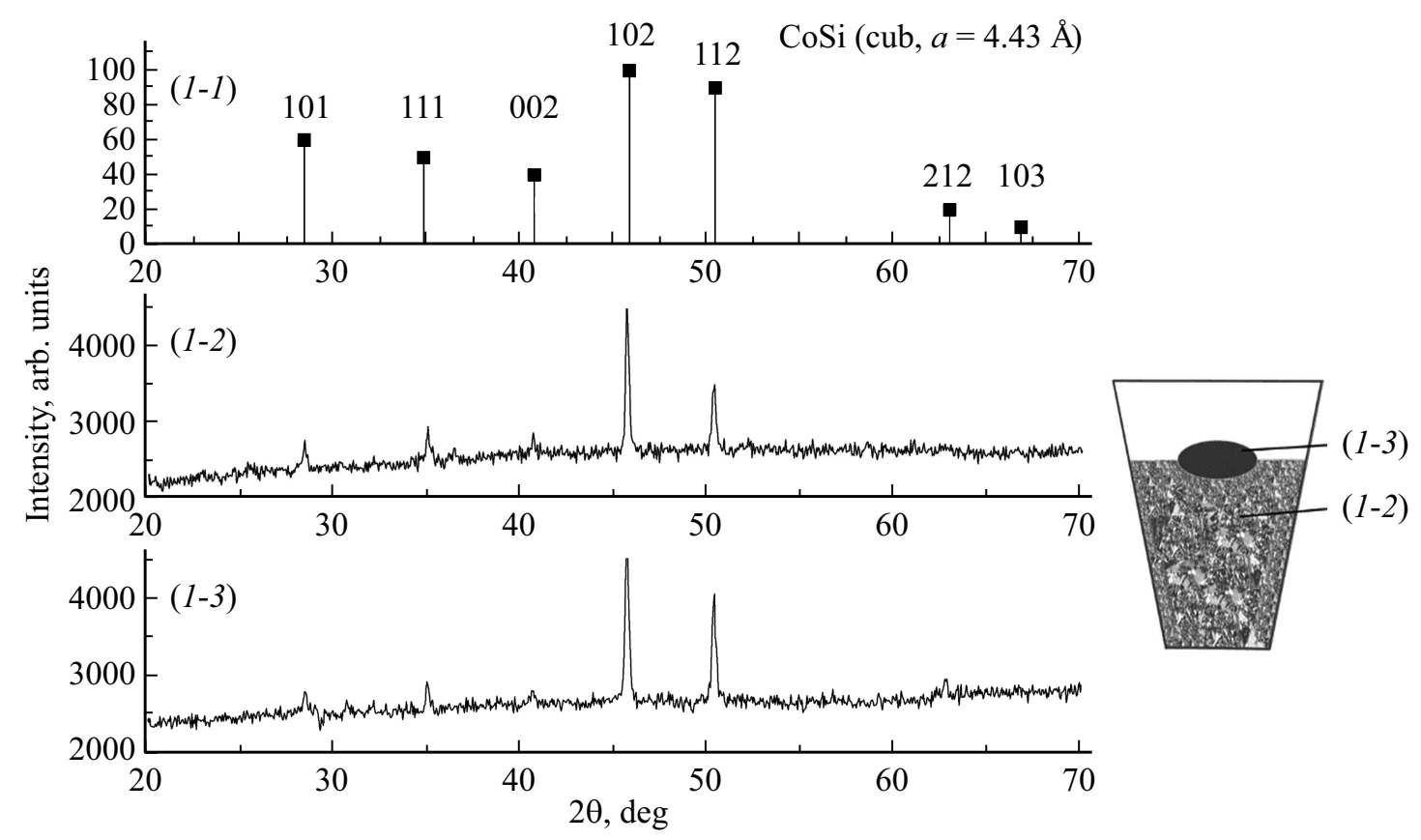

Рис. 1. Контейнер с синтезированным материалом и рентгеновские спектры микрокристаллов $(1-2)$ и поликристалла $(1-3)$. $(1-1)$ - расчетная штрих-дифрактограмма CoSi кубической модификации (cub). (1-2) - порошкограмма микрокристаллов, кристаллизующихся в обьеме РP. (1-3) - порошкограмма поликристалла, сформировавшегося на поверхности РР.

Температурные зависимости термоэдс и электропроводности измерялись с использованием образцов, приготовленных из поликристаллического слитка и из микрокристаллов. Для приготовления образцов из микрокристаллов они измельчались в кварцевой ступке, с помощью сита отбиралась фракция с размерами от 40 до 315 мкм и помещалась в графитовую пресс-форму. Далее методом горячего прессования в вакууме под давлением 500 кг/см ${ }^{2}$ и температуре $1180 \mathrm{~K}$ получали шайбы диаметром 2 см и толщиной $0.8-1 \mathrm{~cm}$, из которых вырезали образцы нужных размера и формы. Образцы поликристаллического слитка вырезали из слитка электроэрозионной резкой.

Измерения термоэдс и электропроводности проводили на автоматизированной установке в интервале температур от 100 до $800 \mathrm{~K}$. Сопротивление было измерено 4-зондовым методом на постоянном токе, а для измерения термоэдс использован дифференциальный метод [6]. Измерения проводились в атмосфере чистого гелия.

\section{3. Экспериментальные результаты}

На рис. 1 представлены рентгеновские спектры микро- и поликристаллов, а также расчетная штрихдифрактограмма $\mathrm{CoSi}$ кубической модификации. При сопоставлении рентгеновских спектров (1-2) и (1-3) со штрих-дифрактограммой видно, что они соответствуют $\mathrm{CoSi}$ кубической сингонии.

Микрокристаллы силицида кобальта, формирующиеся в объеме РР, обладают выраженной кристаллической огранкой, имеют преимущественно игольчатую форму и достигают в длину сотен мкм (рис. 2). Микроскопическое исследование поперечного среза образца из прессованных микрокристаллов CoSi показало, что между микрокристаллами имеется большое количество пор. Анализ элементного состава микрокристаллов показал наличие включений олова.

Микроструктура поликристаллического образца (,линза“) - столбчатая (рис. 3). Направление роста элементов микроструктуры совпадает с направлением

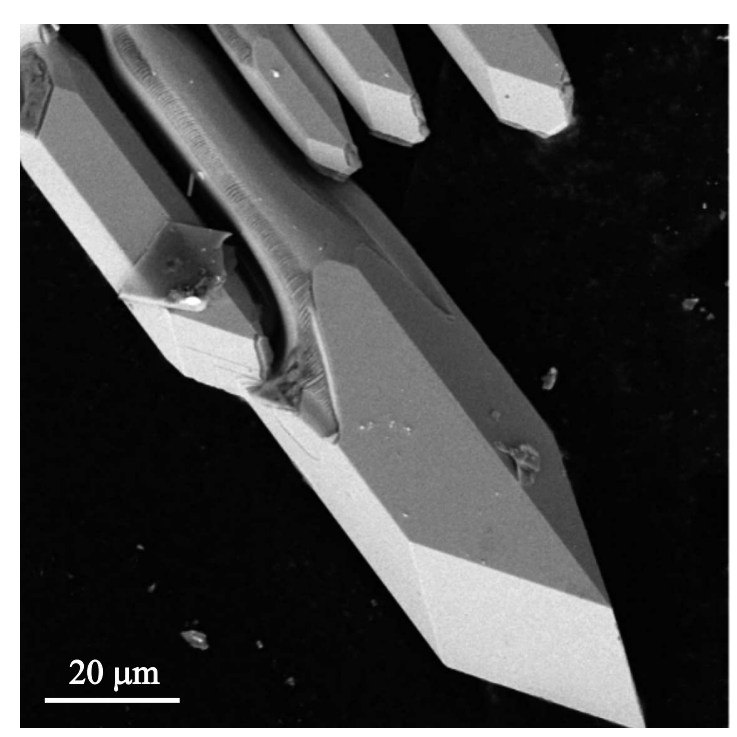

Рис. 2. РЭМ-изображения микрокристаллов, формирующихся в обьеме РP. 


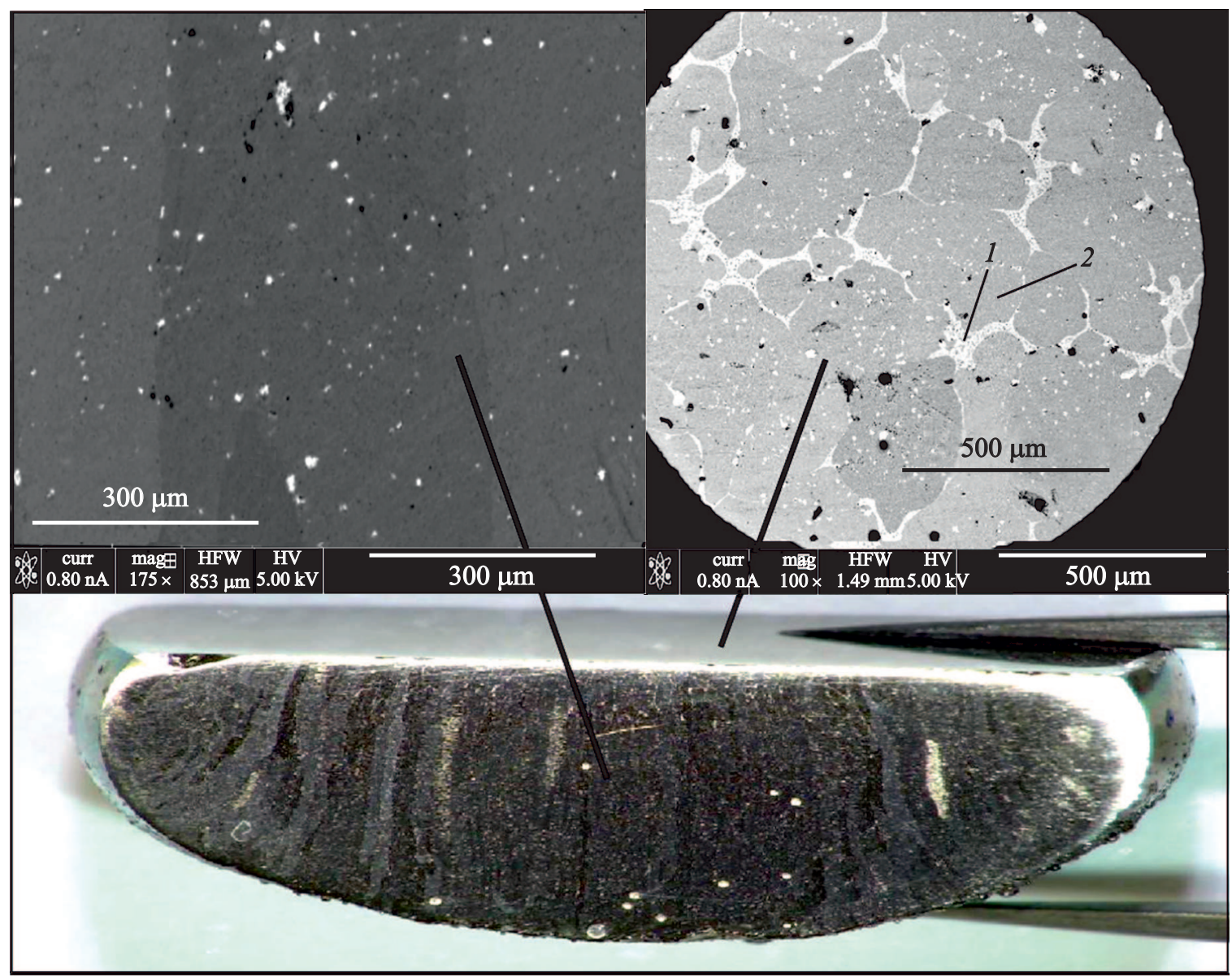

Рис. 3. РЭМ-изображения „линзы“ поликристаллического силицида кобальта в ортогональных направлениях и ее фазовый состав: $1-\mathrm{CoSi}_{0.7}$ (светлое поле), $2-\mathrm{CoSi}_{1.1}$ (темное поле).

температурного градиента при охлаждении РP. Локальный анализ элементного состава поликристаллического силицида кобальта, закристаллизованного на поверхности РР олова, показал, что он в основном состоит из двух фаз $-\mathrm{CoSi}_{0.7}$ и $\mathrm{CoSi}_{1.1}$, с примесью обогащенных оловом включений (рис. 3). Две основные фазы на рис. 3 различаются цветом и имеют четкую границу раздела $\left(1-\mathrm{CoSi}_{0.7}, 2-\mathrm{CoSi}_{1.1}\right)$. Следует отметить, что состав обеих основных фаз отличается от состава стехиометрических соединений $\mathrm{Co}_{2} \mathrm{Si}$ и $\mathrm{CoSi}$.

Термоэлектрические характеристики (термоэдс и электропроводность) измерялись на поликристаллическом материале, закристаллизованном на поверхности PP, и на прессованных микрокристаллах, кристаллизующихся в обьеме РР. Температурные зависимости термоэдс $S$ и электропроводности $\sigma$ поликристалла показаны на рис. 4. Максимальное значение фактора мощности $S^{2} \sigma$ наблюдается при $450 \mathrm{~K}$ и составляет 35 мкВт $/\left(\mathrm{K}^{2} \cdot \mathrm{cm}\right)$. Свойства этого материала близки к свойствам стехиометрического $\mathrm{CoSi}$ [7]. Температурные зависимости термоэдс и электропроводности прессованных микрокристаллов показаны на рис. 5. Максимальное значение фактора мощности для прессованных микрокристаллов наблюдается при $480 \mathrm{~K}$ и составляет $4.5 \mathrm{M \kappa} \mathrm{BT} /\left(\mathrm{K}^{2} \cdot \mathrm{cm}\right.$, что значительно меньше, чем для поликристалла. Низкое значение фактора мощности связано в основном с низкой элек-

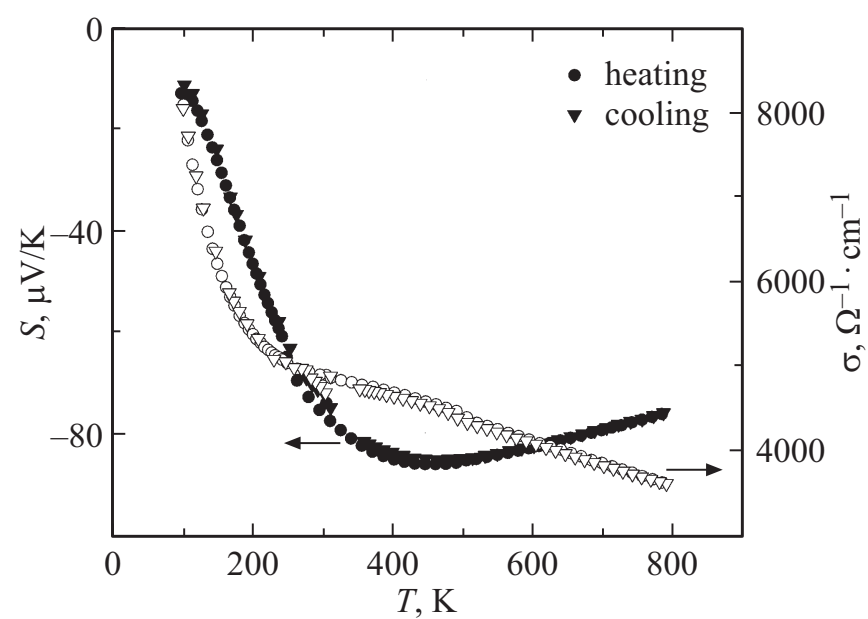

Рис. 4. Температурные зависимости термоэдс $S$ и электропроводности $\sigma$ поликристаллического $\mathrm{CoSi}$, кристаллизованного на поверхности РP. 


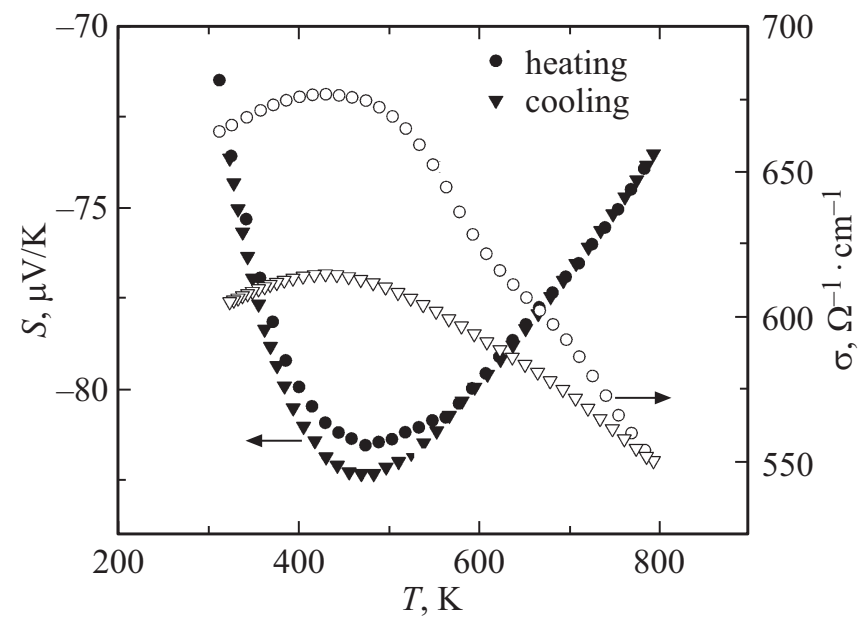

Рис. 5. Температурные зависимости термоэдс $S$ и электропроводности $\sigma$ прессованных микрокристаллов.

тропроводностью: в поликристаллическом образце электропроводность при комнатной температуре близка к $5000 \mathrm{OM}^{-1} \cdot \mathrm{cm}^{-1}$, а электропроводность прессованного образца не превышает $670 \mathrm{OM}^{-1} \cdot \mathrm{cm}^{-1}$. При этом его термоэдс почти совпадает с термоэдс поликристалла. Следовательно, основной причиной низкой электропроводности является пористая структура прессованного образца. Кроме того, кривые нагрева и охлаждения для электропроводности не совпадают. Видно, что после отжига сопротивление образца увеличилось при неизменной термоэдс. Это может указывать на рост сопротивления границ микрокристаллов из-за образования непроводящего оксида в процессе термического отжига.

\section{4. Заключение}

Показана возможность синтеза из пересыщенного РP в олове микро- и макрокристаллического силицида кобальта. Термоэлектрические свойства полученного поликристаллического моносилицида кобальта близки к свойствам этого соединения, синтезированного прямым сплавлением. Максимальное значение термоэлектрического фактора мощности достигает 35 мкВт/ $\left(\mathrm{K}^{2} \cdot \mathrm{cm}\right)$.

Работа выполнена при частичной финансовой поддержке Министерства науки и высшего образования в рамках выполнения работ по Государственному заданию с использованием оборудования ЦКП ФНИЦ „Кристаллография и фотоника““ РАН в части получения электронно-микроскопических данных.

\section{Список литературы}

[1] M.I. Fedorov, V.K. Zaitsev. Thermoelectric Handbook: Macro to Nano, ed. by D.M. Rowe (2006) 31.1.

[2] T.B. Massalski, H. Okamoto, P.R. Subramanian, L. Kacprzak. Binary Alloy Phase Diagrams, 2nd edn. (ASM, Materials Park, OH, 1990) v. 2, p. 1235.
[3] A. Sakai, F. Ishii, Y. Onose, T. Yasuhide, Y. Satoshi, A. Hideaki, N. Naoto, T. Yoshinori. J. Phys. Soc. Jpn., 76, 093601 (2007).

[4] D.A. Pshenay-Severin, Y.V. Ivanov, A.T. Burkov, S.V. Novikov, V.K. Zaitsev, H. Reith. J. Electron. Mater., 47 (6), 3277 (2018).

[5] D.A. Pshenay-Severin, Y.V. Ivanov, A.A. Burkov, A.T. Burkov. J. Phys.: Condens. Matter, 30, 135501 (2018).

[6] A.T. Burkov, A. Heinrich, P. P. Konstantinov, T. Nakama, K. Yagasaki. Measurement Sci. Technol., 12, 264 (2001).

[7] G.T. Alekseeva, V.K. Zaitsev, A.V. Petrov, V.I. Tarasov, M.I. Fedorov. Sov. Phys. Solid State, 23, 1685 (1981).

Редактор Л.В. Шаронова

\section{Structure and thermoelectric properties of CoSi obtained from a supersaturated solution-melt in Sn}

\author{
F.Yu. Solomkin ${ }^{1}$, A.S. Orekhov ${ }^{2}$, 3, S.V. Novikov' ${ }^{1}$, \\ N.A. Arkharova ${ }^{2}$, G.N. Isachenko ${ }^{1}$, N.V. Zaitseva ${ }^{1}$, \\ N.V. Sharenkova ${ }^{1}$, A.U. Samunin ${ }^{1}$, \\ V.V. Klechkovskaya ${ }^{2}$, A.T. Burkov ${ }^{1}$ \\ ${ }^{1}$ loffe Institute, \\ 194021 St. Petersburg, Russia \\ 2 Shubnikov Institute of Crystallography, \\ Federal Scientific Research Centre \\ „Crystallography and Photonics“, \\ Russian Academy of Sciences, \\ 119333 Moscow, Russia \\ ${ }^{3}$ National Research Centre „Kurchatov Institute“, \\ 123182 Moscow, Russia
}

Abstract The structure and thermoelectric properties of cobalt monosilicide prepared by crystallization from a supersaturated solution-melt (SSM) in tin were studied. The method of the synthesis and directed crystallization of microcrystalline and bulk materials in a single technological cycle is developed. 